\title{
Assessment of a Structural Health Monitoring technique through synthetic data generation
}

\author{
Riccardo Panciroli \\ Niccolò Cusano University \\ Via don Carlo Gnocci 3, Rome \\ Engineering Faculty
}

This work assesses the accuracy of a structural health monitoring (SHM) technique previously presented in the literature. The SHM technique under exam relies on a modal decomposition method and is intended to reconstruct the distributed deflection and strain fields from point-wise strain measurements at known locations. The objective of this work is to assess the reliability of such algorithm to variations of sensors number and their location. To this aim, the problem of a simply supported beam subjected to an impulsive loading is solved analytically and the results are used as synthetic input data for the SHM algorithm. The robustness of the SHM methodology has been also evaluated against erroneous choices of modal basis. Results show that sensors number and location play a primary role in the accuracy of the reconstruction, whereby the choice of the modal basis has a negligible influence on the results.

Keywords: SHM, modal decomposition, strain sensors, deformation reconstruction, dynamic response

\section{INTRODUCTION}

The evaluation of stress distribution over complex structures, as well as its overall evolution in time is of major interest in many engineering fields. Therefore, much effort is being dedicated to the development of Structural Health Monitoring (SHM) techniques to serve for this purpose. Major objective is to gain as much information as possible on the entire structure, being the live monitoring of the stress over the whole structure the limit goal. Indeed, direct live measurement of the stress and strain field on the entire structure is impractical; alternative methods must therefore be established.

Many efforts have been dedicated to the development of SHM techniques for the prediction of the displacement and the stress field in structures [1], or for the non-destructive monitoring of internal damages [2-6]. In this work, we assess the reliability and we comment the potential of a SHM methodology proposed in [7] and recently utilized in [8,9], by using synthetic data. The SHM method proposed in [8,9] suggests using a low number of local strain measurements to reconstruct the overall deflection and distributed strain field over an entire structure. The method relies on a modal decomposition technique, where the overall deformation is decomposed over a finite number of mode shapes. Therein, a deep analysis of the influence of the chosen modal basis and sensors locations is lacking.

Contrary to what presented in [7-9], where fiber Bragg gratings (FBG) [10-12] are utilized to experimentally measure punctual strains on vibrating

Received: May 2016, Accepted: June 2016

Correspondence to: Dr Riccardo Panciroli

University of Niccolò Cusano

Via Don Carlo Gnocchi 3, 00166 Rome, Italy

E-mail: Riccardo.panciroli@unicusano.it

doi:10.5937/fmet1604340P

(c) Faculty of Mechanical Engineering, Belgrade. All rights reserved structures, we here generate synthetic data through analytical solutions. Objective of this work is assessing the capability of such SHM methodology to correctly reconstruct the distributed deflection and strain fields and give indications on the optimal location and number of FBG (or strain sensors in general). In the analytical and numerical analyses, we'll respect the technological limitations imposed by the use of FBG sensors for the strain measurements in terms of maximum number and minimum distance between the sensors.

The work is divided in three main sections. Initially, we assess the capability of the reconstruction methodology to correctly predict the structural deflection and strain fields as a function of number of sensors. Within this analysis, we assume to perfectly know the effective mode shapes of the structure. Then, we evaluate the influence of sensors location on the accuracy of the results. At last, we will study the effect of choosing a wrong set of mode shapes on the reconstruction algorithm..

\section{PROBLEM STATEMENT}

Final objective of this study is to assess the reliability of the SHM presented in [8,9] to variations of sensors number, location, and modal basis utilized for the reconstruction. Here, we will study a simple geometry, such as a simply supported beam undergoing an impulsive event in the form of a distributed pressure pulse.

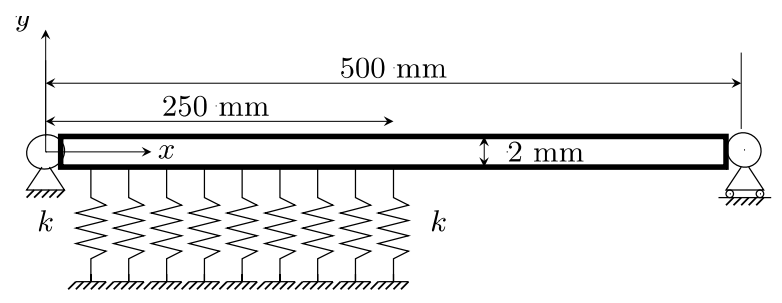

Figure 1: Schematics of the problem studied here.

FME Transactions (2016) 44, 340-347 340 
To add uncertainty to the problem we will introduce an elastic foundation to a portion of the beam, so that the actual mode shapes modifies from the one of a pure simply supported beam. Such condition is representative of all those situations where external factors might influence the mode shape of a structure, e.g. during fluid-structure interaction [13-17], where the fluid acts as an added mass $[18,19]$, or of those situations where the effective boundary condition of the structure are unknown. A sketch of the problem studied here is presented in figure 1 .

\section{SYNTHETIC DATA GENERATION}

\subsection{Analytical model}

For the development of the analytical model, it is assumed that the structural deflection can be decomposed over a finite number of mode shapes following Galerkin [20] method. We further assume that the effective mode shapes of the body match exactly with the theoretical ones.

Following [21], when the characteristic time of an impulse applied to a structure is largely lower than the first natural period of the structure, the shape of the impulse has negligible effect on the response of the first mode shape. The structural response is thus only influenced by the overall energy content of the impulse and not by its time evolution. We can therefore define a reference impulse which is representative for a multitude of load events (e.g. slamming events [2226]). We will here only study a square impulse with constant magnitude of $10 \mathrm{kPa}$ and a duration of $1 \mathrm{~ms}$. Such load condition is representative of a so-called pink noise, exciting a set of frequencies varying from zero to an upper bound which is inversely proportional to the impulse duration.

The governing equation of a plate subjected to an external load varying in space and time $p(x, t)$ is given by $[26,27]$

$$
D w^{I V}(x, t)+\rho_{a} h \ddot{w}(x, t)=-p(x, t)
$$

within this model, the deflection $\mathrm{w}(\mathrm{t})$ is given by:

$$
w(x, t)=\sum_{i=1}^{N} a_{i}(t) \phi_{i}(x)
$$

where $\phi \mathrm{i}$ is the $\mathrm{i}$-th mode shape, ai its modal coordinate, and $\mathrm{N}$ the number of mode shapes considered in the analysis. For a simply supported beam, or a simply supported plate undergoing cylindrical bending, the mode shapes are given by:

$$
\phi_{i}(x)=\sin \left(i \frac{\pi x}{L}\right)
$$

being $L$ the length of the beam. We will here refer to these analytical mode shapes as reference values, whereby we will utilize numerical solutions to evaluate the mode shapes of the beam on the elastic foundation, as detailed later on.

Substituting (2) into (1), multiplying by $\phi i(x)$, integrating over the length of the plate, and considering the orthogonality of the mode shapes, we obtain the following set of $\mathrm{N}$ independent differential equations:

$$
\begin{aligned}
& \ddot{u}_{i}(t) \rho h \int_{0}^{L} \phi_{i}^{2}(x) d x+a_{i}(t) D \int_{0}^{L} \phi_{i}(x) \phi_{i}^{I V}(x) d x= \\
& -\int_{0}^{L} \phi_{i}(x) p(x, l) d x
\end{aligned}
$$

The solution of the set of these differential equations allows estimating the time evolution of the modal coordinates $a_{i}$. The distributed deflection field is then estimated through (2) and the stress field through:

$$
\varepsilon(x, z, t)-\sum_{i-1}^{N} a_{i}(t) \phi_{i}^{\prime \prime}(x) z
$$

being $z$ the distance from the neutral surface.

\subsection{Mode shapes}

The analytical mode shapes, as those presented in (3) for a simply supported beam, might not be always representative of the mode shapes of a real structure. In fact, real structures might be subjected to external factors altering their dynamic response. As title of example, the boundary conditions might not be perfectly defined, or there might be an interaction with the surroundings, like in fluid-structure interactions. All these uncertainties modify the structural response. To account for such uncertainties, we here apply an elastic foundation to a portion of the beam with the intent of modifying the structural dynamics.
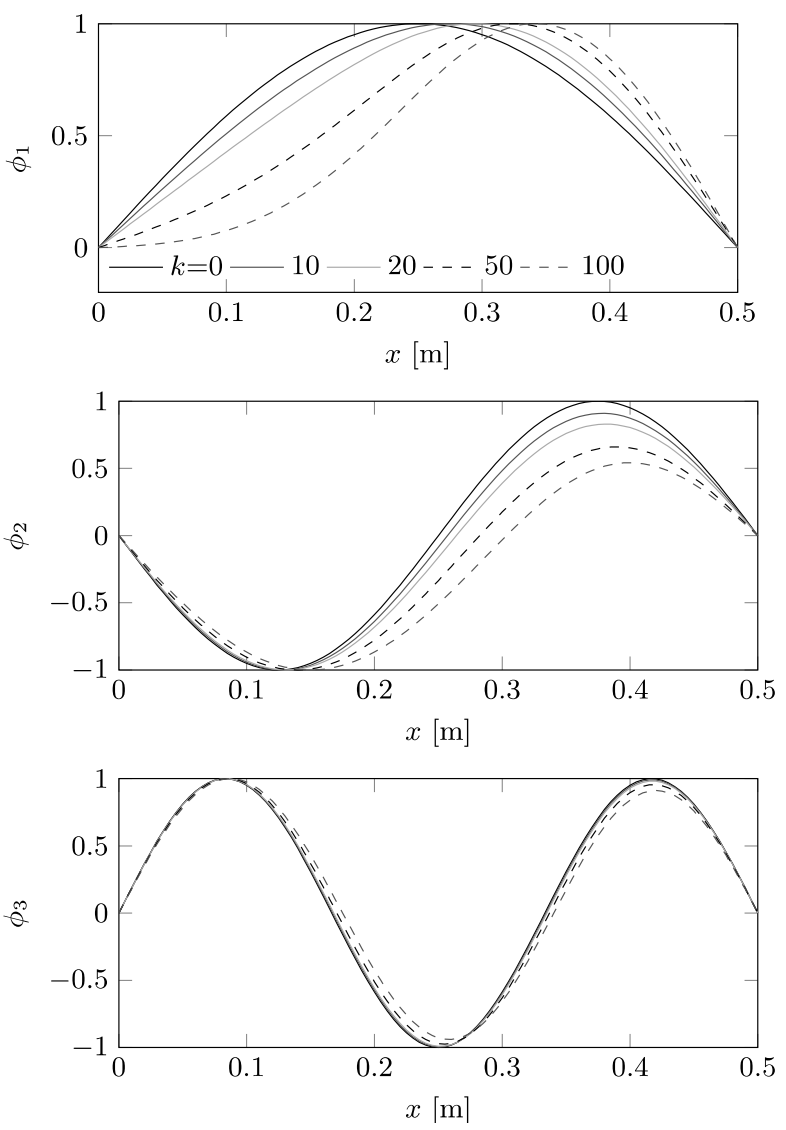

Figure 2: Comparison of the normalized first three deflection mode shapes varying the stiffness of the elastic foundation.

The simply supported beam has been modeled using a finite element model. The beam, $500 \mathrm{~mm}$ long, with a 
rectangular cross sectional area $2 \mathrm{~mm}$ thick and $10 \mathrm{~mm}$ width, has been modeled using 100 beam elements. The simply supported beam lays over a bed of linear springs for half of its length, for a total of 50 springs (one for each node). The nominal length of the springs is 100 $\mathrm{mm}$, whereby we parametrically vary their stiffness $k$ as: $0,10,20,50$, and $100 \mathrm{~N} / \mathrm{m}$, being 0 representative for the reference case of a pure simply supported beam. Please note that these value correspond to a stiffness of $0,20,40,100$, and $200 \mathrm{~N} / \mathrm{mm}$ per unit length of elastic foundation. The first twenty mode shapes of the beam have been estimated through a modal analysis, while the deformation shapes have been evaluated through double differentiation of the mode shapes using a central difference approximation.

The effect of the elastic foundation on the mode shapes is shown in Figure 2. Notably, the difference between the reference mode shapes and the modified ones decreases increasing the mode shape. From the fifth mode shape and above no influence of the elastic foundation is found for the range of $k$ studied here.

We further comment that the difference observed for the mode shapes are further amplified when referring to the curvature, as presented in Figure 3. Therein, we present $\phi^{\prime \prime}{ }_{i}(x)$, which linearly relates to the strain at the measurement locations, that is, $-z \phi^{\prime \prime}{ }_{i}(x)$.

\subsection{Data generation}

The synthetic data are generated solving the set of linear equations presented in (4), where $\rho=2700 \mathrm{~kg} / \mathrm{m}^{3}$ is the density of the beam, $\mathrm{h}=2 \mathrm{~mm}$ its thickness, and $\mathrm{D}=\left[\left(\mathrm{Eh}^{3}\right) /\left(12\left(1-v^{2}\right)\right)\right]$ the flexural modulus, as we assumed the beam to undergo cylindrical bending. The integrals $\int_{0}^{L} \phi^{2}{ }_{i}(x) \mathrm{dx}, \int_{0}^{L} \phi^{I V}{ }_{i}(x) \phi_{i}(x) \mathrm{dx}$, and $\int_{0}^{L} \phi_{i}(x) \mathrm{dx}$ are computed through trapezoidal numerical integration. The set of equations reported in (4) is instead solved using the Runge-Kutta method [28].

The external loading is here fixed to $10 \mathrm{kPa}$ for a duration of $1 \mathrm{~ms}$. The short duration of the pulse allows exciting a high number of mode shapes, which is function of the modal frequencies. For the cases under exam such frequencies are function of the stiffness of the structure, thus of the elastic foundation. As reported in Table 1 and 2, the higher mode shapes get slightly more excited while increasing the stiffness $k$. Table 1 reports the contribution (in \%) of the several mode shapes to the maximum deformation, while Table 2 reports the contribution to the maximum curvature (hence strain).

Notably, the influence of the higher mode shapes increases with $k$, whereby the influence of the fourth mode shape and above is negligible when referring to the displacement. However, higher mode shapes (up to the $7^{\text {th }}$ ) are found to influence the strains, as these relate to the curvature and are thus proportional to $a_{i}(t) \phi_{i}{ }^{\prime \prime}(x)$.

Table 1: Maximum influence of each mode shape on the deflection of the beam expressed as a percentage of the total.

\begin{tabular}{|c|c|c|c|c|c|c|}
\hline$k[\mathrm{~N} / \mathrm{mm}]$ & Mode 1 & Mode 2 & Mode 3 & Mode 4 & Mode 5 & Mode 6 \\
\hline 0 & 95.9 & 0.0 & 3.3 & 0.0 & 0.5 & 0.0 \\
\hline 10 & 93.9 & 1.8 & 3.4 & 0.0 & 0.5 & 0.0 \\
\hline 20 & 91.4 & 4.1 & 3.7 & 0.0 & 0.5 & 0.0 \\
\hline 20 & 82.2 & 12.1 & 4.6 & 0.0 & 0.6 & 0.0 \\
\hline 100 & 71.2 & 21.9 & 5.7 & 0.0 & 0.7 & 0.0 \\
\hline
\end{tabular}

Table 2: Maximum influence of each mode shape on the strain of the beam expressed as a percentage of the total.

\begin{tabular}{|c|c|c|c|c|c|c|}
\hline$k[\mathrm{~N} / \mathrm{mm}]$ & Mode 1 & Mode 2 & Mode 3 & Mode 4 & Mode 5 & Mode 6 \\
\hline 0 & 64.5 & 0.0 & 20.4 & 0.0 & 8.5 & 0.0 \\
\hline 10 & 64.2 & 4.2 & 18.2 & 0.0 & 7.5 & 0.0 \\
\hline 20 & 63.6 & 7.5 & 16.6 & 0.0 & 6.8 & 0.0 \\
\hline 20 & 58.1 & 15.3 & 15.4 & 0.0 & 6.2 & 0.0 \\
\hline 100 & 51.2 & 22.7 & 15.4 & 0.1 & 5.9 & 0.0 \\
\hline
\end{tabular}
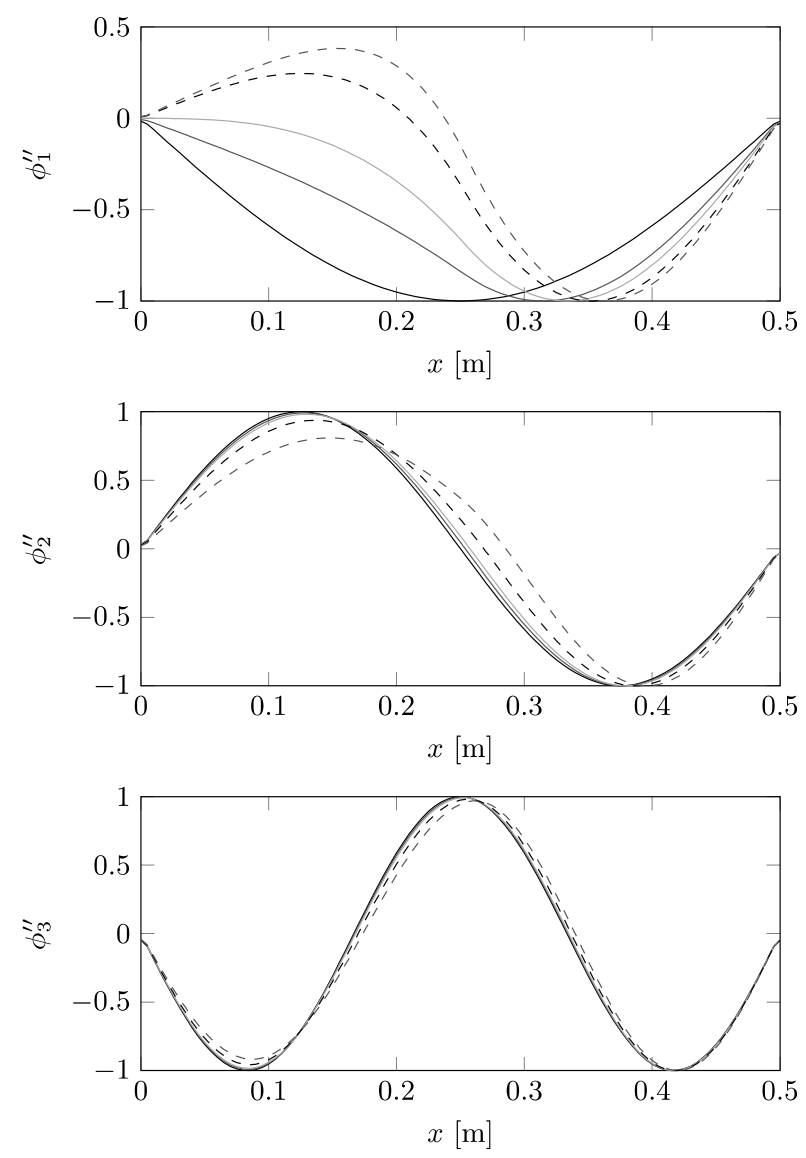

Figure 3: Comparison of the normalized first three curvature mode shapes varying the stiffness of the elastic foundation.

Please note that these results are representative for the particular load case and geometry presented here. However, we should note that the combination of the impulsive load event and the compliant structure studied here allow exciting a high number of mode shapes. Stiffer structures, longer impulses, or the combination of the two, will instead excite a lower number of modes. It can be thus stated that the solution of the example studied here is more challenging than the majority of the possible load events which might act on real structural components.

The set of synthetic data comprises all the information about the time evolution of the overall deflection and strain field, generated from the linear superposition of 20 mode shapes. The available data are continuous in the spatial and the temporal domain.

\subsection{Synthetic strain data at prescribed locations}

In this analysis, we suppose locating a series of strain sensors at prescribed locations on the upper surface of the structure, as schematically drawn in Figure 4. We thus extrapolate the time series of the strain evolution 
from the analytical solution imposing an acquisition frequency of $10 \mathrm{kHz}$. This way, we generate the time series of synthetic strain data at arbitrarily locations to be utilized as input for the reconstruction algorithm presented in $[8,9]$ and not reported here for brevity. The main duty of such SHM technique, which relies on a modal decomposition algorithm, is to reconstruct the overall distributed structural deflection and strains from a finite number of point-wise measured strains at prescribed locations. As single remark, we comment that the number of mode shapes $M$ utilized in the reconstruction algorithm should be lower or equal to the number of strain sensors $N$. In the following, we will always utilize the limit condition $M=N$, that is, we decompose the structural deformation over a number of mode shapes equal to the number of virtual strain sensors.

We parametrically vary the sensors number from 2 to 15 , while their location is prescribed to be equally spaced along the beam length, with a shift of $2.5 \mathrm{~mm}$ on the left, as schematically presented in figure 4 . Such shift is introduced to avoid locations matching with a modal node. In other words, for $M$ sensors, their location is imposed as:

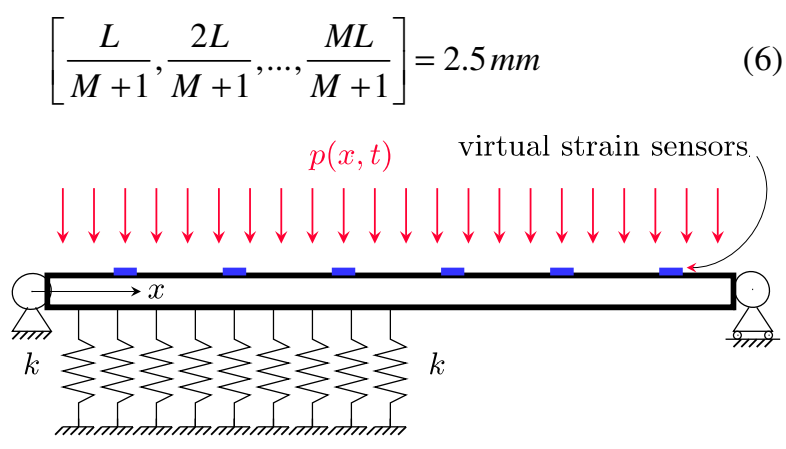

Figure 4: Schematics of the location of the virtual strain sensors.

As already mentioned, only five mode shapes actually contribute to the total deflection. Therefore, we expect the reconstructed solution to be well in line with the original data for a number of strain sensors above five. Contrarily, a lower number of mode shapes accounted in the solution is expected to lead to erroneous reconstructions. The next section introduces the results.

\section{RESULTS}

In this section, we analyse the quality of the reconstruction as a function of the sensors number. Increasing the stiffness of the elastic foundation we note an increase of the frequency of the global response, together with an increasing asymmetry of the solution with respect to the mid-span of the beam. As expected, the maximum deflection is reached in the portion of the beam not supported by the elastic foundation.

Figure 5 reports the comparison between the time traces at the location $x=0.25 \mathrm{~L}$ of the reference deflection data (from the analytical model) and the reconstructed data for varying sensors number (from the SHM reconstruction). To quantify the error between the reconstruction and the original data, we compute the quantity:

$$
\eta_{M}(x)=\frac{1}{T} \sum_{i=1}^{T} \frac{\left|\hat{y}(x, t)-y_{M}(x, t)\right|}{0.5[\max \hat{y}(x, t)-\min \hat{y}(x, t)]}
$$

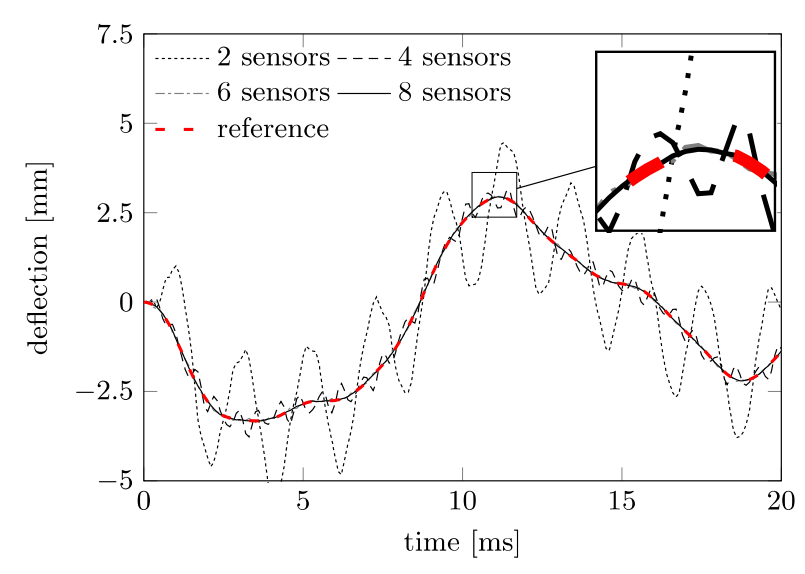

Figure 5: Reference and reconstructed deflection at $0.25 \mathrm{~L}$ varying the number of sensors (hence mode shapes) considered in the analysis. Results are for $k=100 \mathrm{~N} / \mathrm{mm}$.

Being $y(x, t)$ the time evolution of the reference deflection at the location $x$ and $y_{M}(x, t)$ the deflection reconstructed using $M$ sensors (hence $M$ mode shapes). $T$ is the number of time steps considered in the analysis, which here equals 200, as we solved (4) in the interval $0 \div 20 \mathrm{~ms}$ with steps of $0.1 \mathrm{~ms}$. The results are summarized in Table 3. Results are well in line with the expectations, as the reconstruction error decreases while increasing the sensors number. Results show an error below $1 \%$ for any stiffness of the elastic foundation when using a number of sensors above five. This is in line with the results presented in Table 1 , as only five mode shapes were found to influence the deflection.

Table 3: Error $\eta$ (in \%) with respect to the original deflection data.

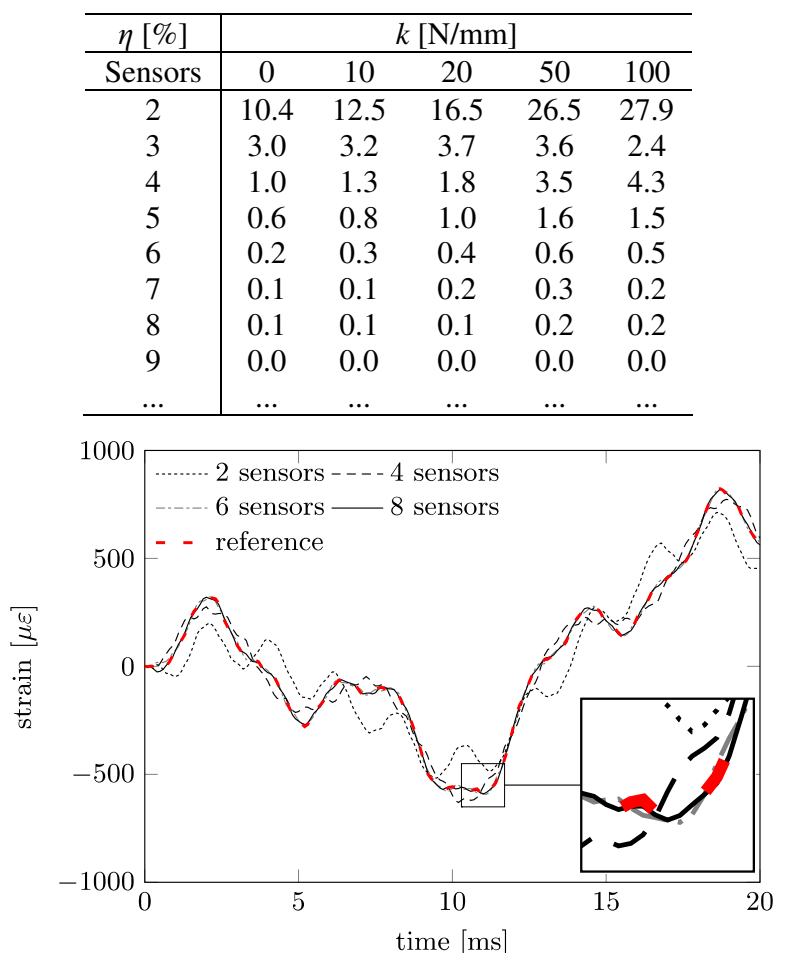

Figure 6: Reference and reconstructed strain at $0.25 \mathrm{~L}$ varying the number of sensors (hence mode shapes) considered in the analysis. Results are for $k=100 \mathrm{~N} / \mathrm{mm}$. 
Table 4: Error $\eta$ (in \%) with respect to the original strain data.

\begin{tabular}{c|ccccc}
\hline$\eta[\%]$ & \multicolumn{5}{|c}{$k[\mathrm{~N} / \mathrm{mm}]$} \\
\hline Sensors & 0 & 10 & 20 & 50 & 100 \\
\hline 2 & 17.2 & 25.4 & 24.0 & 13.5 & 14.0 \\
3 & 17.3 & 24.3 & 21.8 & 10.3 & 7.8 \\
4 & 12.5 & 17.9 & 16.3 & 8.0 & 6.6 \\
5 & 1.5 & 2.2 & 2.0 & 0.9 & 0.7 \\
6 & 1.4 & 2.1 & 1.9 & 0.9 & 0.7 \\
7 & 2.8 & 3.9 & 3.6 & 1.7 & 1.3 \\
8 & 2.1 & 3.0 & 2.7 & 1.3 & 1.0 \\
9 & 0.4 & 0.6 & 0.5 & 0.2 & 0.2 \\
10 & 1.1 & 1.6 & 1.5 & 0.7 & 0.5 \\
11 & 0.2 & 0.3 & 0.3 & 0.1 & 0.1 \\
12 & 0.1 & 0.1 & 0.1 & 0.0 & 0.0 \\
$\ldots$ & $\ldots$ & $\ldots$ & $\ldots$ & $\ldots$ & $\ldots$ \\
\hline
\end{tabular}

Similarly, we can refer to the strain results. Figure 6 shows the comparison between the reference and the reconstructed strains at the same location presented in Figure 5, while Table 4 shows the error computed using 7.

Results about the strain reconstruction are also well in line with the expectations, as it is found that a higher number of sensors is needed to drop the error relative to the reconstructed strain below $1 \%$. In particular, ten mode shapes should be accounted in this case. However, it is worth mentioning that there is a clear threshold when switching between 4 and 5 sensors, as for 5 sensors and above the error drastically diminishes with respect to the four modes approximation.

\section{INFLUENCE OF THE SENSORS LOCATION ON THE QUALITY OF THE RECONSTRUCTION}

Results presented in the previous section show that the reconstruction of the overall deflection is accurate for a sensors number higher than five. Therefore, we here choose $M=6$ and we perform a parametric analysis about the influence of the sensors location on the reconstruction accuracy. The sensor are here equally distributed over a varying portion of the beam in the range:

$$
\left[(10+\Delta) \frac{L}{100} \div 90 \frac{L}{100}\right]
$$

where we parametrically vary $\Delta$ from 0 to 35 . Figure 7 and 8 show contourplots of the error (in \%) defined in (7), for the reconstructed displacement and strain, respectively. Therein, we show the effect of varying the location $x$ and the sensors location. Abscissa report the $x$ location on the beam for which $\eta$ is computed, while the ordinates define the parameter $\Delta$.

In Figure 7 and 8 we also report as a black mark the condition corresponding to the analyses presented in the previous section, while the grey shaded areas represent the beam portion where no virtual strain sensors are located. For a given $\Delta$, a vertical slice of the plot represents the beam length, where sensors have been equally distributed over the white region, whereby no sensors are located along the grey region. The more we move to the right side of the chart, the higher the concentration of sensors in a specific region of the beam. An increasing portion of the beam where no sensors are located is thus associated to moving on the right direction.

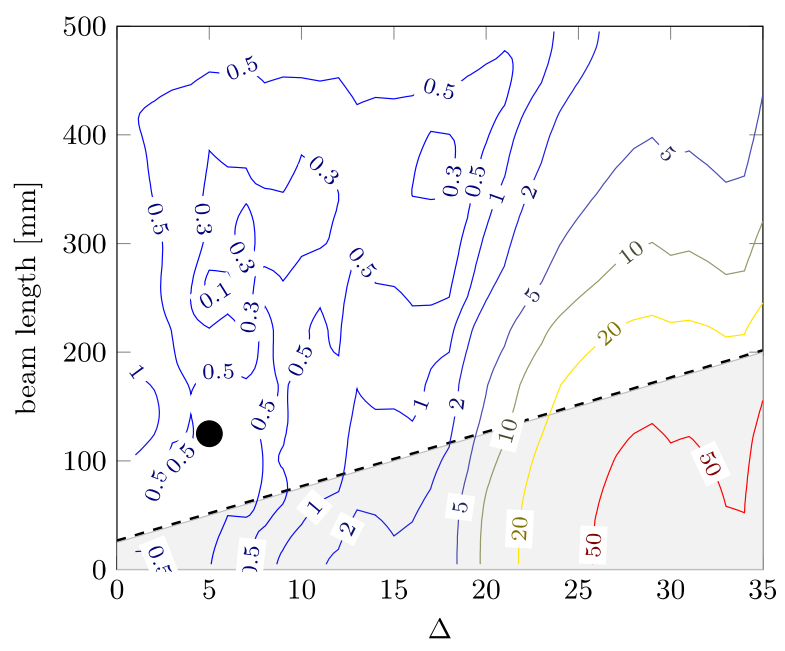

Figure 7: Error $\boldsymbol{\eta}$ (in \%) about the reconstructed deflection for varying location $x$ along the beam length and parameter $\Delta$ defining the sensors location. Results are for $M=6$ and $k=100$.

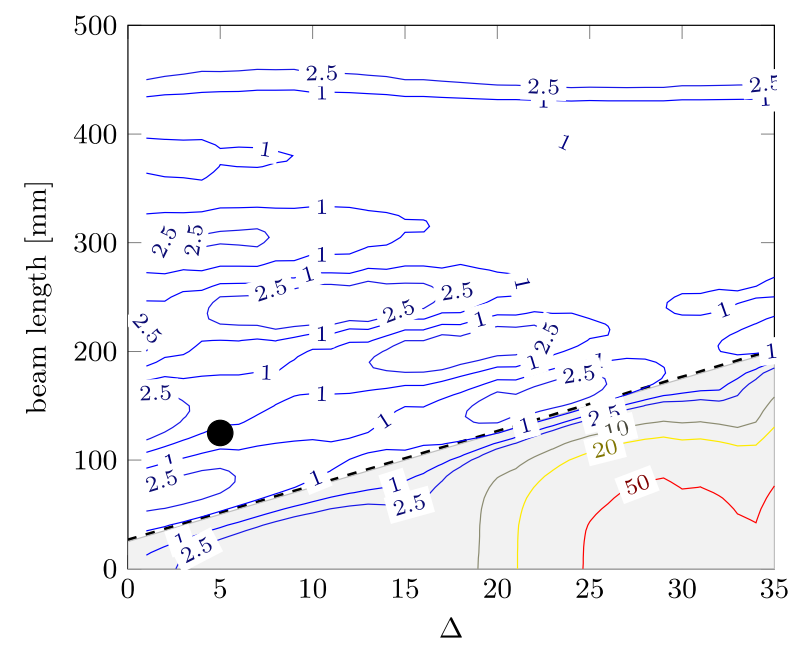

Figure 8: Error $\eta$ (in \%) about the reconstructed strain for varying location $x$ along the beam length and parameter $\Delta$ defining the sensors location. Results are for $M=6$ and $k=100$.

Results clearly show that the optimum condition is attained on the left of the graphs, which means distributing the sensors over the whole beam length. The reconstruction gets worst moving on the right side. In particular, we see that the strain reconstruction is always accurate within the white region, that is, in the proximity of the sensors, but rapidly diverges moving along the grey shaded area, that is, where no sensors have been located. Such error makes the whole deflection reconstruction to fail. In fact, high errors in the grey area lead the deflection to be inaccurate in the white region too.

\section{RECONSTRUCTING OVER AN APPROXIMATE MODAL BASIS}

As mentioned before, the elastic foundation has been introduced to account for modal basis modifications due to external parameters which might modify the dynamic response. Such eventual modification of the modal basis 
might be even unknown. Therefore, we here virtually forget the elastic foundation when using the reconstruction algorithm. We perform an analysis similar to the one detailed above, but we here utilize the original mode shapes instead of the modified one. Synthetic strain data at the virtual measurement locations are generated accounting for the actual mode shapes (beam on elastic foundation), while the reconstruction is performed using the theoretical mode shapes (pure simply supported beam). The mode shapes utilized for the reconstruction are thus not representative for the reality.

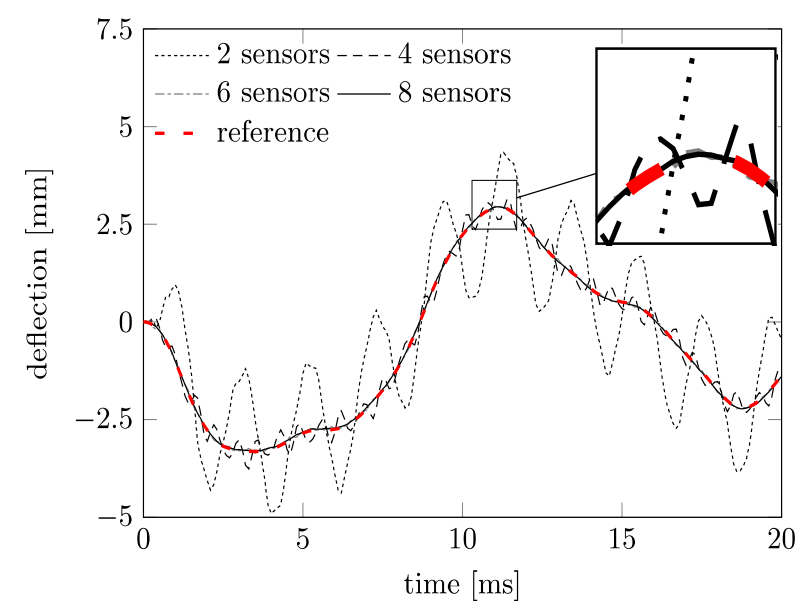

Figure 9: Reference and reconstructed deflection at $0.25 \mathrm{~L}$ varying the number of sensors (hence mode shapes) considered in the analysis. Results are for $k=100 \mathrm{~N} / \mathrm{mm}$.

Table 5: Error $\eta$ (in \%) with respect to the original deflection data using the wrong modal basis. Results are for the case $k=100$

\begin{tabular}{c|ccccc}
\hline$\eta[\%]$ & \multicolumn{5}{|c}{$k[\mathrm{~N} / \mathrm{mm}]$} \\
\hline Sensors & 0 & 10 & 20 & 50 & 100 \\
\hline 2 & 10.4 & 12.3 & 16.4 & 25.7 & 25.4 \\
3 & 3.0 & 3.5 & 4.7 & 7.4 & 7.7 \\
4 & 1.0 & 1.2 & 1.7 & 2.7 & 2.9 \\
5 & 0.6 & 0.8 & 1.0 & 1.6 & 1.5 \\
6 & 0.2 & 0.3 & 0.4 & 0.6 & 0.6 \\
7 & 0.1 & 0.1 & 0.2 & 0.4 & 0.4 \\
8 & 0.1 & 0.1 & 0.1 & 0.2 & 0.2 \\
9 & 0.0 & 0.0 & 0.0 & 0.1 & 0.2 \\
10 & 0.0 & 0.0 & 0.0 & 0.1 & 0.2 \\
11 & 0.0 & 0.0 & 0.0 & 0.0 & 0.0 \\
$\ldots$ & $\ldots$ & $\ldots$ & $\ldots$ & $\ldots$ & $\ldots$ \\
\hline
\end{tabular}

Figure 9 shows the same example presented in Figure 5, but with the reconstruction performed using the wrong modal basis. Notably, no major differences are found about the effects of the sensors number on the quality of the reconstruction. To these associate the errors reported in Table 5. It is interesting to note that, despite the erroneous choice of the modal basis, which is not representative of the reality, the error of the deflection almost vanishes for a sensors number above five, as in the previous analysis.

Similar comments can be drawn for the strain results, as even in this case the error vanishes for a sufficiently high number of strain sensors, as reported in Table 6, which is in line with the reconstruction over the real mode shapes presented in Table 4. Again, the error is found to drastically drop when moving from four to five strain sensors. Please note that the results presented in the above graphs and tables are characteristic for the particular location $\mathrm{x}=0.25 \mathrm{~L}$ chosen here and $\mathrm{k}=100$ $[\mathrm{N} / \mathrm{mm}]$. However, while minor differences of the error values would be found, similar comments can be drawn at any other location.

Table 6: Error $\eta$ (in \%) with respect to the original strain data using the wrong modal basis. Results are for the case $k=100$

\begin{tabular}{c|ccccc}
\hline$\eta[\%]$ & \multicolumn{5}{|c}{$k[\mathrm{~N} / \mathrm{mm}]$} \\
\hline Sensors & 0 & 10 & 20 & 50 & 100 \\
\hline 2 & 17.2 & 24.4 & 22.3 & 10.7 & 9.4 \\
3 & 17.3 & 24.5 & 22.2 & 10.8 & 8.7 \\
4 & 12.5 & 17.9 & 16.3 & 8.1 & 6.5 \\
5 & 1.5 & 2.4 & 2.6 & 1.4 & 1.4 \\
6 & 1.4 & 2.1 & 1.9 & 0.9 & 0.7 \\
7 & 2.8 & 3.9 & 3.6 & 1.8 & 1.4 \\
8 & 2.1 & 3.0 & 2.7 & 1.3 & 1.0 \\
9 & 0.4 & 0.6 & 0.6 & 0.3 & 0.3 \\
10 & 1.1 & 1.6 & 1.5 & 0.7 & 0.6 \\
11 & 0.2 & 0.3 & 0.3 & 0.1 & 0.1 \\
12 & 0.1 & 0.1 & 0.1 & 0.0 & 0.0 \\
13 & 0.1 & 0.1 & 0.1 & 0.0 & 0.0 \\
$\ldots$ & $\ldots$ & $\ldots$ & $\ldots$ & $\ldots$ & $\ldots$ \\
\hline
\end{tabular}

\section{CONCLUSIONS}

In this work, the assessment of the reliability of a SHM technique based on a modal decomposition method has been proposed. In particular, the work focused on the influence of the modal basis, sensors location, and sensors number on the reliability of the data reconstructed through the SHM technique. The problem of a simply supported beam over an elastic foundation subjected to an impulsive load has been solved analytically, to generate synthetic data which are utilized as input for the SHM algorithm.

Results show that there is a minimum number of sensors which needs to be utilized for a reliable reconstruction. This can be defined as the number of mode shapes excited by the impulsive load when referring to the structural deflection. Increasing the number of sensors only slightly increases the accuracy. However, if the distributed strain is on interest, the accuracy of the reconstruction still slightly increases when adding a few more sensors.

An important role is found to be played by the sensors location, as accuracy is found to be maximized when the sensors are distributed over the whole beam and worsen as major portion of the structure have no sensors in the proximity.

At last, the influence of the correctness of the modal basis has been evaluated. Results are extremely interesting, as using an erroneous modal basis is found to have minimal influence on the accuracy of the reconstruction. This is very important for the practical implementation of the SHM technique, as it signifies that unexpected external modification to the structural dynamics will not affect the reliability of the reconstructed data. 


\section{REFERENCES}

[1] C.R. Farrar and K. Worden. An introduction to structural health monitoring. Philosophical transactions. Series A, Mathematical, physical, and engineering sciences, 365(1851):303-15, 2007.

[2] G. Minak, R. Palazzetti, I. Trendafilova, and A. Zucchelli. Localization of a delamination and estimation of its length in a composite laminate beam by the VSHM and pattern recognition methods. Mechanics of Composite Materials, 46(4):387-394, 2010.

[3] I. Trendafilova, R. Palazzetti, and A. Zucchelli. Delamination assessment in structures made of composites based on general signal correlation. International Journal of Structural Stability and Dynamics, 15(1):1440022, 2014.

[4] D. Garcia and I. Trendafilova. A multivariate data analysis approach towards vibration analysis and vibration-based damage assessment: Application for delamination detection in a composite beam. Journal of Sound and Vibration, 338(25):76-90, 2015.

[5] D. Garcia, R. Palazzetti, I. Trendafilova, C. Fiorini, and A. Zucchelli. Vibration-based delamination diagnosis and modelling for composite laminate plates. Composite Structures, 130:155-162, 2015.

[6] I. Trendafilova, R. Palazzetti, and A. Zucchelli. Damage assessment based on general signal correlation. Application for delamination diagnosis in composite structures. European Journal of Mechanics - A/Solids, 49:197-204, 2015.

[7] L. Kang, D. Kim, and J. Han. Estimation of dynamic structural displacements using fiber Bragg grating strain sensors. Journal of Sound and Vibration, 305(3):534-542, 2007.

[8] R. Panciroli, S. Ubertini, G. Minak, and E. Jannelli. Experiments on the Dynamics of Flexible Cylindrical Shells Impacting on a Water Surface. Experimental Mechanics, 55(8):1537-1550, 2015.

[9] R. Panciroli, C. Biscarini, G. Falcucci, E. Jannelli, and S. Ubertini. Live monitoring of the distributed strain field in impulsive events through fiber Bragg gratings. Journal of Fluids and Structures, 61:6075, 2016.

[10] B. Lee. Review of the present status of optical fiber sensors. Optical Fiber Technology, 9(2):57-79, 2003.

[11] J. Leng and A. Asundi. Structural health monitoring of smart composite materials by using EFPI and FBG sensors. Sensors and Actuators A: Physical, 103(3):330-340, 2003.

[12]R. Di Sante, L. Donati, E. Troiani, and P. Proli. Evaluation of bending strain measurements in a composite sailboat bowsprit with embedded fibre Bragg gratings. Measurement, 54:106-117, 2014.

[13] A. De Rosis, G. Falcucci, M. Porfiri, F. Ubertini, and S. Ubertini. Hydroelastic analysis of hull slamming coupling lattice Boltzmann and finite element methods. Computers \& Structures, 138:24-35, 2014.
[14]R. Panciroli and M. Porfiri. A Particle Image Velocimetry Study of Hydroelastic Slamming. Procedia Engineering, 88:180-185, 2014.

[15] R. Panciroli. Water entry of flexible wedges: Some issues on the FSI phenomena. Applied Ocean Research, 39:72-74, 2013.

[16] R. Panciroli and M. Porfiri. Hydroelastic impact of piezoelectric structures. International Journal of Impact Engineering, 66:18-27, 2014.

[17] E. Poodts, R. Panciroli, and G. Minak. Design rules for composite sandwich wakeboards. Composites Part B: Engineering, 44(1):628-638, 2013.

[18]S. Abrate. Hull Slamming. Applied Mechanics Reviews, 64(6):060803, 2013.

[19] R. Panciroli, S. Abrate, and G. Minak. Dynamic response of flexible wedges entering the water. Composite Structures, 99:163-171, 2013.

[20] A. Leissa. Vibration of plates. The Acoustical Society of America, 1993.

[21] R. Panciroli and S. Abrate. Dynamic response of sandwich shells to underwater blasts. Open Engineering, 2(4):509-522, 2012.

[22]R. Panciroli and M. Porfiri. Evaluation of the pressure field on a rigid body entering a quiescent fluid through particle image velocimetry. Experiments in Fluids, 54(12):1630, 2013.

[23] M. Jalalisendi, A. Shams, R. Panciroli, and M. Porfiri. Experimental reconstruction of threedimensional hydrodynamic loading in water entry problems through particle image velocimetry. Experiments in Fluids, 56(2):1-17, 2015.

[24] Riccardo Panciroli, A. Shams, and M. Porfiri. Experiments on the water entry of curved wedges: High speed imaging and particle image velocimetry. Ocean Engineering, 94:213-222, 2015.

[25] R. Panciroli, S. Abrate, G. Minak, and A. Zucchelli. Hydroelasticity in water-entry problems: Comparison between experimental and SPH results. Composite Structures, 94(2):532-539, 2012.

[26] R. Panciroli and M. Porfiri. Analysis of hydroelastic slamming through particle image velocimetry. Journal of Sound and Vibration, 347:63-78, 2015.

[27]L. Meirovitch. Fundamentals of vibrations. McGraw-Hill, New York, N.Y., 2000.

[28] J.C. Butcher and G. Wanner. Runge-Kutta methods: some historical notes. Applied Numerical Mathematics, 22(1-3):113-151, 1996.

\section{ТЕХНИКЕ ПРОЦЕНЕ И ПРАЋЕЊА ТЕХНИЧКЕ ИСПРАВНОСТИ СТРУКТУРЕ ПУТЕМ ГЕНЕРИСАЊА СИНТЕТИЧКИХ ПОДАТАКА}

\section{Р. Панцироли}

Овај рад процењује тачност технике структурног здравственог надзора која је раније представљена у 
литератури. Техника структурног здравственог надзора под испитивањем се ослања на методи модалног разлагања и има за циљ да реконструише расподелу извијања и поље деформација од одвојених мерења деформација на познатим локацијама. Циљ овог рада је процена поузданости таквог алгоритма на варијације броја сензора и њихових локација. У том циљу, проблем једноставно ограничене греде изложене импулсивном оптерећењу је решен аналитичким путем и резултати су искоришћени као синтетички улазни подаци за СХМ алгоритам. Робусност методологије СХM је такође процењена у односу на вредности погрешних избора модалних основа. Резултати показују да број сензора и локација играју главну улогу за тачност реконструкције, чиме избор модалне основе има занемарљив утицај на резултате. 